\title{
Pedagogia do oprimido e extensão rural: Iniciativas de empoderamento feminino no Seridó paraibano
}

CAMPOS, Cynthia de Lima'

\section{Resumo}

Dentre as metodologias apontadas pela Política Nacional de Assistência Técnica e Extensão Rural (PNATER), considerada a nova ATER, e orientada pelos "princípios do desenvolvimento sustentável, incluindo a diversidade de categorias e atividades da agricultura familiar, e considerando elementos como gênero, geração e etnia" (BRASIL, 2003), destacam-se a pedagogia da alternância e a pedagogia do oprimido, esta última discutida em livro homônimo pelo seu criador, o pedagogo Paulo Freire (2013), que, grosso modo, defende uma educação que possa dar ao educando a capacidade de se reconhecer como oprimido, para então, somente nesses moldes libertar-se da opressão. Nessa perspectiva, as mulheres agricultoras, podem ser consideradas, ao menos duas vezes, submissas à opressão: pelo capitalismo, cuja face se revela no agronegócio, e pelos seus próprios companheiros, dadas as condições de desigualdade no campo. Assim, com base na pedagogia do oprimido, a pesquisadora adentrou, com as devidas permissões, no assentamento Fortuna, localizado na cidade de Cuité, Seridó paraibano, com o objetivo de levar formação às mulheres da comunidade, de modo a lhes oferecer a possibilidade de empoderamento, sobretudo por meio da obtenção de uma renda. Foram realizadas visitas orientadas pelo Diagnóstico Rural Participativo, bem como visitas in loco. Ao longo das intervenções, algumas dificuldades foram se colocando, das quais destacou-se o fato de que boa parte das mulheres não havia pensado na possibilidade de empoderamento a partir da comercialização de sua produção. Ademais, o número de extensionistas que chegam a tais comunidades levando promessas quase nunca cumpridas, acaba por estimular a desconfiança em qualquer iniciativa. Aos poucos, as mulheres foram aderindo à proposta, levando à oficialização de uma marca para comercialização dos produtos. Nesta etapa do processo, os resultados obtidos são muito mais de ordem política, no sentido de entendimento dessas mulheres sobre a importância do empoderamento, do que de fato pela geração de renda, que ainda se encontra em estado incipiente.

\section{Pedagogia do Oprimido. Extensão Rural. Empoderamento Feminino. Mulheres Agricultoras. Agricultura Familiar.}

Pedagogy of the oppressed and rural extension: Initiatives of female empowerment in the micro-region of Seridó paraibano

\section{Abstract}

Among the methodologies pointed out by the National Policy of Technical Assistance and Rural Extension (PNATER), considered the New ATER, and guided by "the principles of sustainable development, including the diversity of categories and

\footnotetext{
1 Doutora em Sociologia pela Universidade Federal de Pernambuco. Professora do Curso Superior em Agroecologia e do Curso de Especialização em Gestão de Recursos Ambientais no Semiárido do Instituto Federal de Educação, Ciência e Tecnologia da Paraíba, campus Picuí. E-mail: cynthia.Icampos@gmail.com
} 
activities of family agriculture, and considering elements such as gender, generation and ethnicity" (BRASIL, 2003), the pedagogy of alternation and the pedagogy of the oppressed are highlighted, the latter discussed in a book of the same name by its creator, the pedagogue Paulo Freire (2013), who, roughly speaking, defend an education that can give the student the ability to recognize himself as oppressed, for then, only in these ways to free oneself from oppression. In this perspective, women farmers can be considered, at least twice, subject to oppression: by capitalism, whose face is revealed in the agribusiness, and by their own companions, due to the conditions of inequality in the field. Thus, based on the pedagogy of the oppressed, the researchers entered, with the appropriate permissions, in the Fortuna settlement, located in the city of Cuité, Seridó of Paraíba (Brazil), with the objective of training the women of the community, in order to offer them the possibility of empowerment, especially by earning an income. Visits were guided by the Participatory Rural Diagnosis, as well as visits in loco. Throughout the interventions, some difficulties were placed, of which it was highlighted the fact that many of the women had not thought about the possibility of empowerment from the commercialization of their production. In addition, the number of extensionists who arrive at such communities carrying promises almost never fulfilled, ends up stimulating distrust in any initiative. Gradually, the women were adhering to the proposal, leading to the officialisation of a brand to commercialize the products. In this stage of the process, the results obtained are much more of a political order, in the sense of the understanding of these women on the importance of empowerment, than in fact by income generation, which is still in an incipient state.

Pedagogy of the Opressed. Rural Extension. Women Empowerment. Women Farmers. Family Agriculture.

\section{Introdução}

Historicamente, a extensão rural brasileira beneficiou muito mais 0 agronegócio do que o pequeno agricultor, quadro este que só veio a ser revisto a partir do que muitos chamam de Nova ATER (Assistência Técnica e Extensão Rural). A própria nomenclatura - ATER - não separa a ação pontual da Assistência Técnica, que tem conotação de produtividade, desempenho, eficiência, da ação educativa Extensão Rural, que dentro dos princípios da nova ATER, e associada a uma ação pedagógica, deve estar muito mais relacionada à transformação de comunidades rurais a médio e longo prazo. Fato é que em mais de cem anos de extensão rural no Brasil, somente nos últimos dezesseis anos é que surgiram políticas públicas que privilegiassem 0 empoderamento dessas comunidades por meio dessas ações pedagógicas.

A Política Nacional de Assistência Técnica e Extensão Rural (PNATER) surge com uma proposta orientada pelos "princípios do desenvolvimento sustentável, incluindo a diversidade de categorias e atividades da agricultura familiar, e considerando elementos como gênero, geração e etnia" (BRASIL, 2003), com metodologias construídas com base nas diversas realidades vivenciadas na agricultura familiar em todo território nacional. Orientadas pela pedagogia do oprimido (FREIRE, 2013) e pela pedagogia da alternância, na prática essas ações se materializam no Diagnóstico Rural Participativo (DRP), privilegiando o potencial endógeno das comunidades. 
A nova ATER, sobretudo as ações de extensão, podem ser desempenhadas tanto pelo setor público quanto pelo setor privado, além do terceiro setor, representado pelas Organizações Não Governamentais (ONGs) e pelas Organizações Rurais $(\mathrm{ORs})^{2}$. No entanto, o financiamento é em sua maior parte, advindo do setor público.

Apesar de todo esse esforço em atender a agricultura familiar por meio desta nova ATER, o que se observou foi um sucateamento das entidades destinadas a este fim, como a EMATER-PB, por exemplo. Como concluiu Monteiro, em pesquisa realizada junto a assentamentos do Curimataú paraibano (2016),

Há uma ausência da assistência técnica que contribui para a falta de orientação efetiva, o que aumenta a distância entre agricultores familiares e agentes financeiros, dificultando 0 acesso a financiamentos para investir em alternativas sustentáveis e compatíveis com a realidade da agricultura familiar como, por exemplo, manejos agroecológicos. Este tipo de dificuldade desestimula os assentados a procurarem meios para contornar a situação de inadimplência e não deixarem suas propriedades.

Mesmo nos assentamentos e comunidades rurais onde já se registra a presença de profissionais extensionistas, também foram observadas insatisfações por parte dos assentados e assentadas no que diz respeito à imposição de pacotes tecnológicos, sem que se antes a comunidade seja ouvida, e muito menos sem se levar em consideração as necessidades da comunidade. Alguns casos merecem registro, como a Comunidade Quilombola Serra do Abreu, localizada na divisa da cidade de Picuí com Nova Palmeira, também região do Curimataú paraibano, em que uma ONG da região pleiteou em 2015 - obtendo êxito - o financiamento de um forno para cerâmica no valor de $R \$ 50.000,00$ (Cinquenta mil reais). No entanto, a atividade cerâmica na comunidade tinha apenas adesão de uma pessoa, não havendo interesse dos demais membros, devido à baixa valorização das peças. Ademais, a comunidade não possuía renda suficiente para arcar com a manutenção de energia elétrica do forno. Outra insatisfação diz respeito à presença de empresas de extensão rural nas comunidades, mas sem se identificar uma ação efetiva, com resultados obtidos pela comunidade, como se identificou no depoimento da presidente da Associação do Assentamento Fortuna (objeto deste estudo): "A gente só faz assinar papel. Eles só vivem levando papel pra gente assinar e mais nada".

2 Organizações Rurais incluem as cooperativas, os sindicatos, tanto patronais quanto de trabalhadores, assim como associações de produtores e criadores. 
Outro ponto relevante para a condução deste trabalho foi a questão de gênero. Se para os agricultores familiares em geral, a extensão rural ainda se encontra ineficiente, como estaria então para as mulheres, relegadas a segundo plano no trabalho produtivo por não terem suas atividades domésticas reconhecidas, o que vem a configurar um trabalho invisível, sem o qual não haveria produção na "roça"?

Assim é que, em nosso primeiro contato com o Assentamento Fortuna, pudemos identificar um número potencial de mulheres assentadas, que não desenvolviam nenhuma atividade com vistas à geração de renda, ou mesmo seu empoderamento. Em todas as cinquenta casas do assentamento a principal fonte de renda ou era o Bolsa Família ou alguma atividade desenvolvida pelos homens, como apicultura, por exemplo.

Desse modo, em setembro de 2017 foi iniciada uma ação de intervenção extensionista norteada pelos princípios da PNATER, tendo como foco as assentadas do Assentamento Fortuna, de modo a conferir-Ihes capacidade para desenvolver atividades de geração de renda e o consequente empoderamento. É importante salientar que a renda gerada dessas atividades não se constitui em um valor que possa ser gerador de riqueza, mas há de se considerar que, por menor que seja a renda, acaba levando um pouco de autonomia a tais mulheres quase sempre dependentes do Estado ou de seus companheiros.

No que segue apresentamos uma breve digressão histórica da ATER no Brasil até se constituir na nova ATER, além dos princípios gerais e da metodologia proposta pela PNATER, com ênfase no DRP e na pedagogia do oprimido. Por fim, apresentamos como as ações foram desenvolvidas no Assentamento Fortuna e os resultados obtidos até o momento presente.

\section{A Extensão Rural no Brasil}

\subsection{Os primórdios}

Primeiramente é importante estabelecer o divisor entre assistência técnica e extensão rural. Enquanto esta se caracteriza por ser um processo educativo, independente do conhecimento a ser repassado, e com resultados a médio e longo prazo, visando sempre a transformação contínua da comunidade, a assistência técnica corresponde a uma ação pontual, para a resolução de um problema pontual, como por exemplo, uma praga que acomete uma plantação, ou a demonstração de funcionamento de uma determinada ferramenta. Nesse sentido, a extensão rural tem viés pedagógico e transformador.

Peixoto (2008), ao apresentar os marcos legais da extensão rural no Brasil, nos chama a atenção para o fato de que esta teve início já no Séc. XIX, a partir da criação dos Institutos Imperiais de agricultura, que além das 
Pedagogia do oprimido e extensão rural: Iniciativas de empoderamento feminino no Seridó paraibano

atribuições de ensino e pesquisa agropecuária também assimilou a incumbência de difusão de informações.

Já no início do Séc. XX, a recriação do Ministério dos Negócios da Agricultura, Indústria e Commercio, por meio do decreto 1.606, de 29 de dezembro de 1906, dava continuidade à preocupação com a disseminação de conhecimento, uma vez que dentre as suas atribuições estavam "comunicação de informações, propaganda, publicidade e divulgação de tudo quanto interessar à agricultura, indústria e commercio no interior e no exterior" (PEIXOTO, 2008, p. 13). O decreto 8. 319, de outubro de 1910, que regulamentou o ensino agronômico, trouxe consigo algumas iniciativas de extensão rural, tais como: cursos ambulantes de agricultura, que tinham por finalidade a instrução profissional dos agricultores que, por circunstâncias especiais se encontravam privados de recorrer aos cursos regulares dos estabelecimentos de ensino agrícola; conferências agrícolas; além dos campos de demonstração, com o objetivo de divulgar os conhecimentos práticos, adquiridos em experimentações anteriores.

No entanto, a literatura especializada (OLINGER, 2006; PEIXOTO, 2008) citam a Semana do Fazendeiro, promovida pela então Escola Superior de Agricultura de Viçosa, em 1929, como sendo a primeira ação de extensão rural institucionalizada no Brasil. Note-se que a própria nomenclatura da ação exclui o pequeno agricultor. Durante a década de 1940, outras ações acabaram por ganhar corpo, a exemplo das semanas ruralistas, surgidas a partir da cooperação entre o Ministério da Agricultura e as secretarias estaduais de agricultura. Ainda nesta década a criação das Casas Rurais, associações rurais municipais, tinha como objetivo:

I) realizar a difusão de ensinamento agropecuários, visando, principalmente, a melhoria das condições do habitat rural;

m) promover a aprendizagem agropecuária, sempre que possível em cooperação com órgãos oficiais;

n) manter na sede um museu com os tipos padrões dos produtos locais de expressão econômica, pugnando pela aplicação das medidas oficiais relativas à padronização e classificação (BRASIL, 1945).

Ainda é importante mencionar as Missões Rurais de Educação, patrocinadas pelo então Ministério da Educação e Saúde, e operacionalizadas pela Igreja Católica. E como aponta Peixoto (2008, p. 17):

Baseavam-se na filosofia do desenvolvimento de comunidades (DC) por processos educativos e assistenciais, e eram compostas por equipes multidisciplinares, constituídas de 
Pedagogia do oprimido e extensão rural: Iniciativas de empoderamento feminino no Seridó paraibano

agrônomos, médicos, sociólogos, psicólogos e assistentes sociais.

Apenas uma dessas missões, a implantada na cidade de Itaperuna(RJ) foi bem-sucedida, dando origem à Campanha Nacional de Educação Rural (CNER), que manteve dezoito missões em funcionamento, sobretudo no Nordeste, tendo durado de 1952 a 1963, já que a metodologia de desenvolvimento de comunidades se mostrou pouco eficiente.

\subsection{A Institucionalização da ATER no Brasil}

Foi ao longo das décadas de 1950 e 1960 que a ATER se institucionalizou efetivamente no Brasil. Exatamente a partir da criação da Associação de Crédito e Assistência Rural (ACAR) em Minas Gerais (1956), sob forte influência do modelo americano, já que houve incentivo financeiro da família Rockfeller (PEIXOTO, 2008, p. 18). Ao longo das duas décadas foram se multiplicando no número de ACARs espalhadas pelo Brasil, surgindo assim a Associação Brasileira de Crédito e Assistência Rural (ABCAR) incumbida de coordenar as ACARs locais, formando do Sistema Brasileiro de Extensão Rural (SIBER).

À medida que as ACAR eram estatizadas e absorvidas pelos Estado onde estavam situadas, ao mesmo tempo em que surgiam as Empresas de Assistência Técnica e Extensão Rural (EMATER), o SIBER foi dando origem ao Sistema Brasileiro de Assistência Técnica e Extensão Rural (SIBRATER), que teve papel importante no desenvolvimento do país.

O Sibrater participou ativamente, nas décadas de 50 a 70 , da promoção da transição do País que, de francamente agrário, com a economia baseada na exportação principalmente de café, passou a industrial, com a adoção do modelo de desenvolvimento rural baseado na difusão de pacotes tecnológicos modernizantes. A modernização da agropecuária foi caracterizada pelo consumo de insumos e equipamentos industrializados. A mecanização intensiva liberou mão-de-obra rural para a indústria e construção civil. As políticas de pesquisa agropecuária, crédito rural e a Ater foram voltadas para o fortalecimento desse modelo, e as estruturas políticoeconômicas favoreceram a produção em grande escala de matéria prima agropecuária, destinada à exportação ou à industrialização (PEIXOTO, 2008, p. 24). 
Embora a Constituição de 1988 determinasse que as políticas públicas agrícolas contemplassem os serviços de ATER, o que se viu foi extinção da EMBRATER por parte do Governo Sarney, que não foi a termo na primeira tentativa porque o setor extensionista reagiu, mas que foi de fato extinta no primeiro dia do Governo Collor. Assim, durante a década de 1990, as ações de extensão rural ficaram muito pulverizadas sob a responsabilidade do então Ministério da Agricultura e Reforma Agrária (MARA).

$\mathrm{Na}$ ausência do apoio federal aos serviços oficiais de Ater e diante da inexistência de uma política nacional para o setor, alguns estados da federação, num esforço de manutenção deste importante instrumento de política pública, reestruturaram os serviços dando-lhes diversas formas institucionais e criando novos mecanismos de financiamento e operacionalização das empresas oficiais, além de apoiarem outras entidades emergentes. Nesse mesmo período, surgiram e se expandiram várias iniciativas, visando suprir a carência e o vácuo deixado pelo Estado, destacando-se aquelas patrocinadas por prefeituras municipais, por organizações não-governamentais e por organizações de agricultores, entre outras (BRASIL, 2004).

Mas foi somente a partir de 2003, a partir do decreto 4.739 que o então Ministério de Desenvolvimento Agrário (MDA) assumiu a responsabilidade dos serviços de ATER no Brasil, antes designados ao Ministério da Agricultura, Pecuária e Abastecimento (MAPA), que relegou a segundo plano ações de ATER. Outro ponto importante a ser mencionado e que veio contribuir fortemente para o que se caracteriza com Nova ATER são as possibilidades de crédito e financiamento que o pequeno agricultor pode obter, além da implementação da PNTER e do Programa Nacional de Assistência Técnica e Reforma Agrária (PRONATER), estes construídos de forma participativa, contemplando agentes dos diversos setores que compõem o meio agrário (PEIXOTO, 2008).

\section{Ações de Extensão Rural no Assentamento Fortuna}

\subsection{Caracterização da Comunidade}

O Assentamento Fortuna, localizado na cidade de Cuité, Seridó paraibano, possui 50 famílias, entretanto apenas 5,3\% das beneficiárias participaram tanto das entrevistas individuais quanto das coletivas. As mulheres entrevistadas tinham entre 25 a 67 anos, com baixo grau de escolaridade, em torno de 3 a 4 anos de estudo. A renda bruta mensal da maioria das assentadas não atinge um salário mínimo, e embora retirem seu sustento da agricultura, devido à escassez hídrica, as assentadas fizeram questão de abordar o quanto se sentem asseguradas por serem beneficiárias do Programa Bolsa Família do Governo Federal. 
Nos tempos de chuva, nóis fazia hortas, trabalhava na roça, e tirava o sustento da agricultura. Mais agora, só temos o bolsa família, e ai de nóis se não fosse isso. (Agricultora, 29 anos)

Veio essa seca de 5 anos e mudou muita coisa moça, meu marido teve que ir embora para nóis num passar necessidade, graças a Deus tenho o bolsa família é o que nos ajuda no final do mês. (Agricultora, 27 anos)

Em tempos de chuva, o assentamento se dedica à produção de queijos e derivados do leite, tomate, hortaliças, pinha, umbu e maracujá. Além da criação de pequenos animais e atividades de apicultura.

\subsection{Metodologia}

O primeiro contato foi obtido através da presidente da associação, em uma reunião na Associação Comunitária de Desenvolvimento Rural Claudio Gervásio Furtado no Assentamento Fortuna, no dia 23 de setembro de 2017. Essa primeira etapa teve como objetivo apresentar a equipe à comunidade e de propiciar um diálogo informal com as assentadas a respeito de como as mesmas sentiam-se em relação à extensão rural.

Ficou muito claro, nesse primeiro contato, a divisão do trabalho sexual no assentamento, uma vez que o convite da reunião foi dirigido somente às mulheres do assentamento, mas pode-se registrar a tentativa de vários homens participarem da reunião, sob a alegação de que não entendiam porque não tinham sido convocados para uma atividade relacionada à extensão rural, e consequentemente, uma atividade produtiva. Como se pode ver na fala do agricultor:

"Nois homem é que precisa mermo" (Agricultor, 45 anos).

A orientação metodológica seguiu as bases da Pedagogia do Oprimido, de Paulo Freire (2013), segundo a qual é preciso levar a consciência ao oprimido das condições, de modo que este possa formular questionamentos em torno do status quo ao qual está submetido. No caso das assentadas do Assentamento Fortuna, as mesmas se encontram duplamente em condição de opressão: por serem pequenas agricultoras numa região de extrema pobreza, e consequentemente se encontram excluídas do universo do consumo de bens de melhor qualidade, possuem renda bem inferior a um salário mínimo mensal, dependem do Estado para terem acesso a serviços básicos, como saúde, educação e até alimentação por meio do Programa Bolsa Família; mas também se encontram oprimidas na sua condição de mulheres agricultoras. 
$\mathrm{Na}$ agricultura, estudos demonstraram que o trabalho familiar ainda mantém desigualdades de gênero, privilegiando o homem-marido enquanto chefe de família e da propriedade. Os homens devem cuidar das atividades produtivas, ou seja, voltadas para o mercado, enquanto consideram que as mulheres apenas "ajudam", o que reflete a desvalorização do trabalho feminino pela sociedade, já que as tarefas domésticas não geram renda monetária. Seu desempenho nessas atividades não é considerado como trabalho, uma vez que não se inclui no mercado de bens e serviços e, assim, não envolve a circulação de recursos monetários. Ao mesmo tempo, elas podem assumir um papel auxiliar nas atividades produtivas, em momentos de falta de mão de obra masculina.

Sua libertação da ditadura da miséria e do controle masculino familiar amplo sobre seus destinos permite-lhes, assim, um mínimo de programação da própria vida, e, nesta medida, possibilita-Ihes o começo da autonomização de sua vida moral.

Assim, urge uma ação de libertação dessas mulheres que possa thes empoderar duplamente, superando a miséria e a desigualdade de gênero. Obviamente, não caímos na ingenuidade de que as mesmas vão constituir fortuna a partir dessas ações de extensão rural, mas a possibilidade de gerar sua própria renda, confere-lhes autonomia e reflete diretamente na sua autoestima.

É nesse momento que se faz valer as orientações da Pedagogia do Oprimido (FREIRE, 2013), qual seja aquela que tem que ser forjada juntamente com o oprimido e não para o oprimido, quando da sua libertação da opressão. "Pedagogia que faça da opressão e de suas causas objeto de reflexão dos oprimidos". Porém, para tanto é preciso o entendimento do oprimido de que o mesmo se constitui "hospedeiro do opressor".

Este modelo de educação deve possibilitar ao oprimido não apenas 0 entendimento da sua condição, mas a superação dessa condição, porque a libertação não pode se dar apenas de maneira idealista, deve-se extinguir a realidade da opressão. Superar tal condição (e contradição) traz ao mundo o sujeito não mais opressor, não mais oprimido, mas o sujeito em libertação. Conferir às mulheres do Assentamento Fortuna a possibilidade de autonomia, mesmo que pela obtenção de uma pequena renda, fruto do seu trabalho, também é libertar os homens do assentamento da condição de opressor.

No entanto, Freire (2013) reconhece a possibilidade do oprimido, ou não se reconhecer na condição de opressão, ou reconhecer-se, mas vivenciar 0 que ele chama de dualidade.

Descobrem que não sendo livres, não chegam a ser autenticamente. Querem ser, mas temem ser. [...] Sua luta se 
trava entre serem eles mesmos ou serem duplos. Entre expulsarem ou não ao opressor de dentro de si. Entre se desalienarem ou se manterem alienados. [...] Entre serem expectadores ou atores. Entre atuarem ou terem a ilusão que atuam, na atuação dos opressores. Entre dizerem a palavra ou não terem voz, castrados no seu poder de criar e recriar, no seu poder de transformar o mundo (FREIRE, 2013).

Corrobora com esta orientação de Paulo Freire, a metodologia apresentada pela PNATER (BRASIL, 2004, p. 6).

\begin{abstract}
Os serviços públicos de Ater (realizados por entidades estatais e não estatais) devem ser executados mediante o uso de metodologias participativas, devendo seus agentes desempenhar um papel educativo, atuando como animadores e facilitadores de processos de desenvolvimento rural sustentável. Ao mesmo tempo, as ações de Ater devem privilegiar o potencial endógeno das comunidades e territórios, resgatar e interagir com os conhecimentos dos agricultores familiares e demais povos que vivem e trabalham no campo em regime de economia familiar, e estimular o uso sustentável dos recursos locais. Ao contrário da prática extensionista convencional, estruturada para transferir pacotes tecnológicos, a nova Ater pública deve atuar partindo do conhecimento e análise dos agroecossistemas e dos ecossistemas aquáticos, adotando um enfoque holístico e integrador de estratégias de desenvolvimento, além de uma abordagem sistêmica capaz de privilegiar a busca de equidade e inclusão social, bem como a adoção de bases tecnológicas que aproximem os processos produtivos das dinâmicas ecológicas.
\end{abstract}

Na prática, essa metodologia se reverbera, entre outras, no uso do DRP no sentido de valorizar o potencial endógeno de cada comunidade, uma vez que o seu propósito é incentivar a própria comunidade a identificar as suas necessidades no sentido de recebimento de assistência técnica e extensão rural.

\title{
2.3 Mulheres e Extensão Rural
}

Como já mencionado acima, nosso primeiro contato ocorreu no dia 23 de setembro de 2017. O objetivo foi o de apresentar a equipe à comunidade e de propiciar um diálogo informal com as assentadas a respeito de como as mesmas sentiam-se em relação à extensão rural.

$\mathrm{Na}$ roda de conversa, foram surgindo sugestões por parte das mulheres de atividades que as mesmas poderiam desenvolver no assentamento, com o 
Pedagogia do oprimido e extensão rural: Iniciativas de empoderamento feminino no Seridó paraibano

propósito de geração de renda e consequentemente melhorias da autoestima, empoderamento e ocupação das assentadas.

Esta reunião deixou bastante clara a necessidade de uso do DRP como a ferramenta mais adequada de se trabalhar com a comunidade, permitindo que as próprias mulheres identificassem suas capacidades e limitações, exatamente porque

O DRP pretende desenvolver processos de pesquisa a partir das condições e possibilidades dos participantes, baseando-se nos seus próprios conceitos e critérios de explicação. Em vez de confrontar as pessoas com uma lista de perguntas previamente formuladas, a ideia é que os próprios participantes analisem a sua situação e valorizem diferentes opções para melhorá-la (VERDEJO, 2010, p. 12).

A segunda fase do DRP foi constituída de entrevistas individuais semi estruturadas que foram realizadas no mês de outubro de 2017, com apenas uma parcela de 13 famílias, com finalidade de proporcionar um maior esclarecimento em relação ao assunto proposto no primeiro contato, e através da aplicação de um questionário que almejou conhecer mais as assentadas, em relação à sua história pessoal, à renda familiar, histórico de trabalho e suas expectativas no tocante a novas atividades geradoras de renda.

Em busca de dar seguimento ao DRP, iniciamos uma terceira fase executada por meio de grupos focais com as possíveis beneficiárias, no sentido de definir os produtos que seriam produzidos e posteriormente comercializados. Embora houvesse uma motivação coletiva, a divergência em torno do que se produzir estava presente, uma vez que algumas mulheres preferiam a produção artesanal, outras a produção de doces, queijos e geleias e outras a produção agrícola. Daí a necessidade de participação da comunidade, de modo que esse problema seja solucionado pelas próprias assentadas, sem a imposição ou influência dos agentes de ATER.

Finalmente se decidiu que todos os itens seriam comercializados, com exceção de produtos artesanais, a dificuldade que agora surgia era como comercializar. Nesta etapa, as reuniões contavam aproximadamente com a presença de dez a doze mulheres.

Com base nesse questionamento, buscou-se curso de capacitação para comunidade, de modo que todos os assentados e assentadas fossem contemplados. Nesse momento, ficou claro como de fato a mera existência de políticas públicas não é suficiente para fomentar o desenvolvimento de comunidades rurais em condições de extrema pobreza. Primeiramente, fizemos uma busca na região de alguma ONG que pudesse oferecer o curso 
gratuitamente, nenhuma manifestou interesse, sob a alegação de não possuir técnico com tal expertise. O próximo passo foi procurar o Sebrae, que a despeito da dificuldade de encontrar uma data adequada para a pesquisadora, o próprio Sebrae e as assentadas e assentados, agendou o curso para a primeira semana de fevereiro de 2018. No entanto, o curso não pode ser ministrado porque a comunidade deveria repassar-lhe a quantia de dois mil reais pelo curso. $\mathrm{O}$ curso somente pode ser ministrado porque a equipe contou com a colaboração voluntária de uma Agroecóloga da região, que repassou informações referentes à certificação de produtos de base agroecológica.

Concomitantemente, durante nossos encontros, descobriu-se que o assentamento já possuía CNPJ de associação, o que facilitou bastante no momento de se pensar uma marca a ser agregada aos produtos. A comunidade contratou um designer que criou uma logomarca a ser utilizada na embalagem dos produtos (Figura 1).

FIGURA 1: Logomarca dos Produtos Fortuna

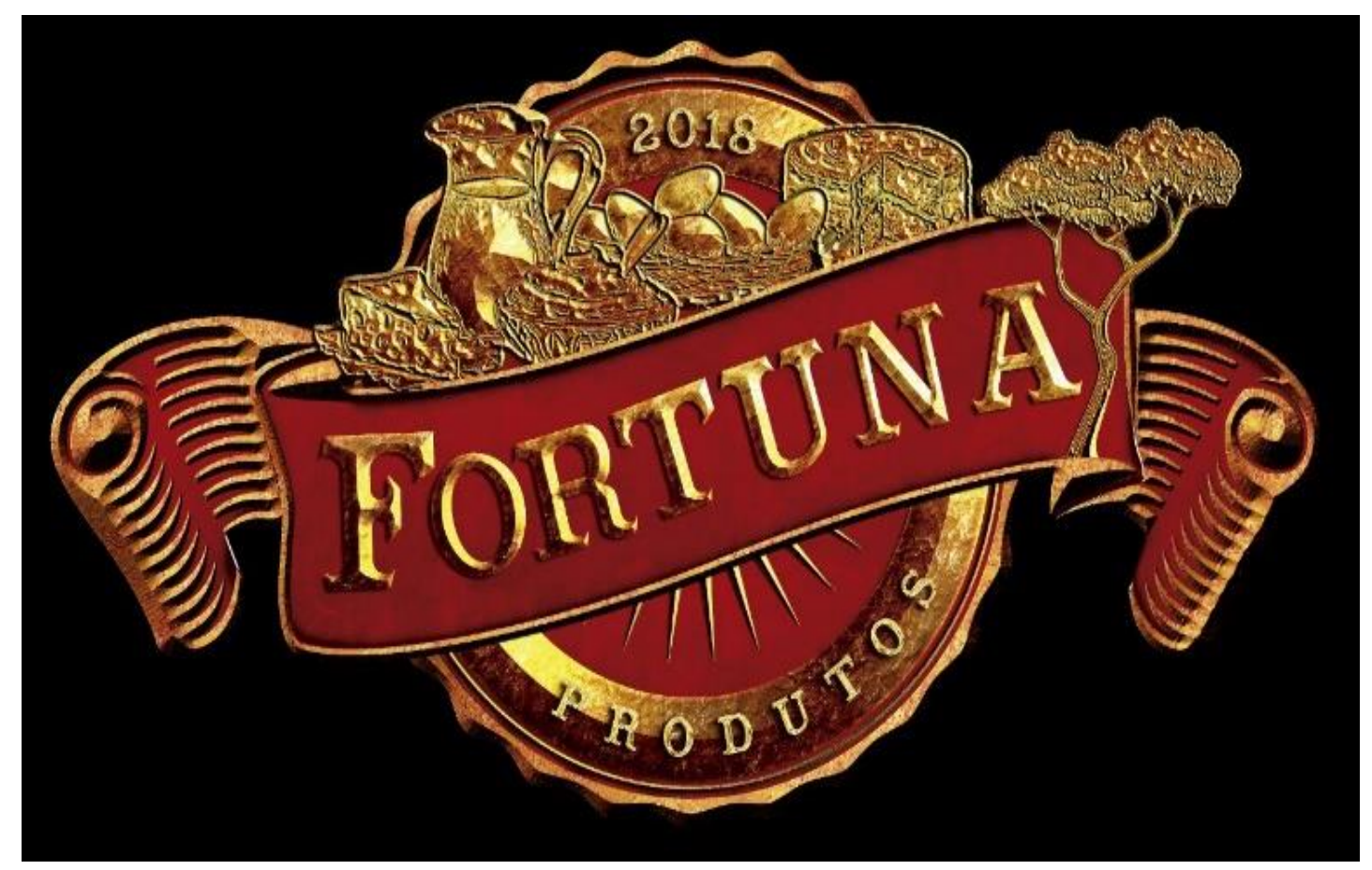

Fonte: Acervo pessoal

A última fase da intervenção constituiu-se na divulgação das mercadorias, pinha, doces, feijão verde, umbu, pimenta, maxixe e acerola, que foi realizada através da rádio rural 87.9 FM-Baraúna, Paraíba. Após a divulgação, as agricultoras, agora apenas três, passaram a comercializar os seus produtos na feira livre da cidade de Cuité. 
Pedagogia do oprimido e extensão rural: Iniciativas de empoderamento feminino no Seridó paraibano

\section{Considerações Finais}

Do primeiro contato estabelecido até a comercialização final dos produtos foram corridos nove meses, comprovando que uma ação de extensão efetiva deve ocorrer no mínimo a médio prazo, exatamente porque a extensão deve ser uma ação pedagógica de transformação dos membros de uma dada comunidade.

O descrédito nas políticas públicas, por parte destas comunidades ainda se faz presente, seja pelo despreparo dos e das extensionistas, seja pelo próprio descaso dos mesmos, o que ocasionou a resistência por parte da maioria das beneficiárias a participarem do projeto de extensão.

\footnotetext{
"Aqui todo mundo é esquecido, e tudo é difícil e quem não estudou para ser alguém na vida só sabe o que é agricultura moça. Esse negócio de assistência nós num tem não, os técnicos vêm e trás um monte de papel pra nós assinar e pronto". (Agricultora 3, 31anos).
}

Mas não apenas a ausência de extensionistas seria o motivo pela resistência das assentadas a aderirem a intervenção. Paulo Freire explica muito bem essa resistência quando mostra que nem todos os oprimidos e oprimidas estão dispostos a enfrentarem tal condição, porque esse enfrentamento é uma condição de luta, e até de agonia, por isso na maior parte das vezes, os oprimidos e oprimidas se recusam a enxergar a sua condição e consequentemente lutar pela superação desta. Veja-se que num assentamento com 50 famílias, apenas três mulheres chegaram à etapa final da comercialização dos produtos. A maioria alegou falta de tempo. Outras realmente reconheceram que não acreditavam mais. "Essas pessoas que chegam aqui e só pede pra gente assinar papel, mas a situação nunca muda" (Agricultora 4, 35 anos)

É preciso reconhecer também as limitações da nossa intervenção que foi completamente voluntária, no sentido de não ter recebido nenhum financiamento que pudesse ser direcionado para capacitações da comunidade. Ainda assim, acreditamos que pelo menos estas três agricultoras puderam experienciar um pouco de autonomia e consequente empoderamento. E que não pare por aqui.

\section{Referências}

BRASIL. Leis, decretos, etc. Decreto-Lei no 7.449, de 9 de abril de 1945. Dispõe sobre a organização da vida rural. Brasília, 1945. Disponível em: <http://www.planalto.gov. br/ccivil_03/decreto-lei/Del7449.htm>. 
Pedagogia do oprimido e extensão rural: Iniciativas de empoderamento feminino no Seridó paraibano

Política Nacional de Assistência Técnica e Extensão Rural. Brasília, 2004.

FREIRE, Paulo. Pedagogia do oprimido. 23. Ed. Petrópolis: Vozes, 2013.

MONTEIRO, Emanuelly de Souza. Análise qualitativa da assistência técnica prestada aos assentamentos rurais da reforma agrária no município de Picuí-PB. 2016. 50 fls. Monografia (Agroecologia). IFPB, campus Picui, 2016.

OLINGER, Glauco. Ascensão e decadência da extensão rural no Brasil. Florianópolis: EPAGRI, 1996.

PEIXOTO, Marcus. Extensão rural no Brasil: uma abordagem histórica da legislação. Brasília: Senado Federal, 2008.

VERDEJO, Miguel Expósito. Diagnóstico Rural Participativo: guia. Brasília: MDA, 2010. 